\title{
Contextos e Questões da Avaliação Psicológica
}

\author{
Alícia Maria Hernández Munhoz
}

Sisto, F. F.; Sbardelini, E. T. B. \& Primi, R. (orgs.). 2001. Contextos e questões da avaliação psicológica. São Paulo: Casa do Psicólogo, 235 p.

O presente livro reflete a crescente preocupação com a área de avaliação psicológica no Brasil. Essa coletânea de textos, quatorze ao todo, apresenta um panorama interessante de avanços, questões e críticas a respeito do diagnóstico, tanto no contexto clínico quanto no escolar, assim como dos instrumentos e das teorias. Apesar da diversidade, contudo, a forma como foi organizado permite estabelecer uma relação de um capítulo para o outro.

O livro inicia com o capítulo de Rita Romaro sobre o diagnóstico em terapia breve. A autora apresenta um estudo de caso utilizando como instrumento diagnóstico a Escala Diagnóstica Adaptativa Operacionalizada (EDAO). Demonstra a eficiência da escala para o levantamento dos aspectos a serem enfocados na terapia assim como na avaliação de seus efeitos. A autora ainda esclarece que, apesar da qualidade do instrumento, este ainda depende da experiência clínica do profissional e sugere mais estudos de validade e precisão. Cabe ressaltar a preocupação da autora em verificar sistematicamente a qualidade dos resultados alcançados no processo terapêutico.

O segundo capítulo, de autoria de Sebastián Urquijo, traz uma breve revisão de teorias da personalidade e dos respectivos métodos de avaliação para então introduzir os modelos circumplexos da personalidade e um dos instrumentos baseados nesse modelo, o Inventário Clínico Multiaxial de Millon-II - MCMI-II (Millon, 1999). Especialmente elaborado para avaliação clínica e psicopatológica, o MCMI-II permite identificar transtornos de personalidade (Eixo II) e as síndromes clínicas (Eixo I) de forma correlata aos DSM-III e IV, o que o torna também interessante para uso em pesquisa.

Ainda abordando a avaliação dos transtornos de personalidade no terceiro capítulo, Sonia Regina Loureiro apresenta uma análise crítica dos termos relacionados à saúde e aos transtornos mentais e às respectivas classificações dos CID-10 E DSM-IV. Aponta a dificuldade da identificação e avaliação dos transtornos de personalidade, confundidos com estilos de vida, às vezes aceitáveis nos dias atuais. A autora explicita a limitação das classificações diagnósticas que, por sua característica puramente descritiva, deixa de lado os aspectos dinâmicos da personalidade. Ressalta a urgência de mais pesquisas na área para a elaboração de instrumentos mais adequados para sustentar o psicodiagnóstico e assegurar os aspectos éticos relacionados à questão.

Cláudio Capitão, no quarto capítulo, faz uma análise sobre o abuso sexual de crianças. Através de uma leitura psicanalítica, busca entender os processos dinâmicos que levam pais a agredir sexualmente seus filhos pequenos assim como as seqüelas na personalidade infantil. $O$ autor relata que quando a criança é vítima desse tipo de violência por parte dos pais, em momento tão precoce, essa experiência pode ser ressignificada posteriormente deslocando-se para figuras adultas substitutas. Um exemplo do efeito desse processo foi o caso da Escola de Base em São Paulo. O autor aponta o problema de se realizar uma avaliação com crianças pequenas dadas as dificuldades de se diferenciar fantasia e realidade.

No quinto capítulo, Anna Elisa de Villemor Amaral Güntert, em ressonância aos questionamentos apresentados por Sonia Loureiro, cita pesquisas recentes realizadas com técnicas projetivas, principalmente com o Teste de Rorschach, apontando que pode haver um caminho alternativo para a dicotomia entre uma visão classificatória normativa, como a do DSM-IV, e a outra mais idiossincrática clínica. A autora ressalta que, apesar dos avanços, muito ainda precisa ser feito no sentido de tornar essas técnicas mais confiáveis.

Abrindo a parte destinada à área escolar, Elizabeth Sbardelini apresenta um texto destinado à orientação profissional utilizando o Teste de Fotos de Profissões BBT (Achtnich, 1991). O instrumento procura estabelecer os aspectos dinâmicos, organizados em oito fatores, que levam à escolha profissional, através da observação e análise das reações do sujeito em relação às fotografias, quer sejam de identificação, de rejeição ou ambivalência. Ao concluir o texto reforça o cuidado com a coerência teórico-metodológica na utilização de instrumentos.

O sétimo capítulo, de Cristina Joly, aborda um dos aspectos fundamentais da educação, a competência em leitura. A autora afirma que esta é alcançada quando o sujeito consegue processar informações além do texto imediato denotando criatividade e criticidade. Relata pesquisas sobre os efeitos de programas para a promoção e desenvolvimento de habilidades de leitura, dando especial destaque aos que se utilizam da literatura. Retoma a questão da avaliação apresentando estudos 
com a técnica de Cloze. Ressalta que, em vista das inovações tecnológicas, em especial a multimídia, deve-se repensar os conceitos de competência em leitura.

O oitavo capítulo, de autoria de Fermino Sisto, traz uma crítica aos processos e instrumentos de avaliação psicoeducacional em uso no Brasil. Os avanços da psicologia cognitiva apontam para novos caminhos na área, como a avaliação dos processos que subjazem o desenvolvimento acadêmico e intelectual, a saber: atenção, motivação, estilos de aprendizagem e metacognição. Argumenta também da importância dos professores atentarem para esses aspectos no planejamento do seu trabalho, assim como promover a utilização de avaliações padronizadas em complementação das realizadas pelos professores, por apresentarem maior possibilidade de demonstrar as competências dos alunos.

A inteligência emocional, tópico do nono capítulo, é um dos mais recentes conceitos dentro da psicologia. Maurício Hass Bueno e Ricardo Primi relatam, inicialmente, o desenvolvimento desse construto que teve suas bases nos estudos sobre a inteligência. Fazem em seguida uma breve apresentação de alguns dos instrumentos destinados a sua avaliação. Apontam para o cuidado na utilização do termo que já faz parte do jargão popular, assim como a necessidade de desenvolver instrumental adequado baseado em desempenho.

Seguindo as novas tendências em avaliação psicoeducacional apontadas anteriormente por Sisto, os dois capítulos a seguir tratam da construção de instrumentos para avaliação de estilos de aprendizagem e de estilos cognitivos, definidos como maneiras ou formas típicas do indivíduo, respectivamente, se aproximar do conteúdo a ser aprendido (através de observação, atuação, etc) e de utilizar as habilidades cognitivas para aprender (autonomia ou dependência, impulsividade ou reflexibilidade, etc).

Tereza Cerqueira e Acácia Santos, no décimo capítulo, apresentam teorias de estilo de aprendizagem, habilidade fundamental relacionada à capacidade de aprender que reflete aspectos relacionados não somente à cognição mas também à personalidade. Relatam pesquisas realizadas com o inventário de Kolb (1984) apontando para aspectos ainda pouco estudados sobre o tema que merecem atenção sendo amplo campo de estudo.

Isabel Cristina Dib Bariani, Fermino Sisto e Acácia Santos, no capítulo seguinte, focalizam os estilos cognitivos. A literatura apresenta diversas definições do conceito. Percebe-se, contudo, um ponto de convergência: que o estilo cognitivo não é uma capacidade em si mesma mas reflete uma forma preferencial do indivíduo utilizar suas habilidades. Os autores apresentam, em seguida, um estudo sobre a construção e validação de um instrumento para avaliação de estilos cognitivos em universitários. Os resultados comprovam a literatura quanto à dimensão bipolar do estilos. Não corroboraram, contudo, todas as dimensões, o que implica na necessidade de mais estudos.

Encerrando o conjunto de textos destinado a avaliação psicoeducacional, o décimo segundo capítulo conta com oito autores liderados por Fermino Sisto, abordando a criação de uma escala sobre satisfação escolar. Os autores apontam para a escassez de pesquisas focalizando o ensino fundamental e detectando, ainda, a ausência de instrumentos para esse grupo. Com o objetivo de suprir essa lacuna, relatam a construção de um instrumento de satisfação escolar envolvendo alunos da $3^{\mathrm{a}}$ a $8^{\mathrm{a}}$ série.

Destaca-se o capítulo seguinte com o texto de Érica Santarém que acrescenta as contribuições do behaviorismo para a avaliação. A autora apresenta a avaliação funcional do comportamento, parte de um processo amplo de análise funcional, tanto no contexto escolar como no clínico. Atenta para o fato de que melhores instrumentos devem ser construídos focalizando contextos específicos para permitir uma avaliação mais acurada que permita estabelecer formas mais adequadas de intervenção.

Josiane Tonelotto encerra o livro apresentando um aspecto fundamental, principalmente para a área escolar, a avaliação da atenção. Faz uma revisão histórica dos termos relacionados aos problemas de atenção como por exemplo Transtorno do déficit da atenção com ou sem hiperatividade (TDAH). Relata que os critérios presentes no DSM-IV são mais rigorosos e permitem uma melhor identificação do transtorno. Ressalta a autora que o diagnóstico da atenção deve ser multidisciplinar, envolvendo profissionais da saúde e da educação dada a complexidade do fenômeno, e aponta para a urgência de pesquisas no Brasil.

A diversidade de temas relevantes para a área de avaliação psicológica apresentada pelo livro é um dos fatores que o tornam uma leitura interessante e agradável. Os textos estão bem articulados, apresentando um denominador comum, um posicionamento crítico perante a avaliação psicológica, dos instrumentos propriamente ditos e as teorias que os fundamentam.

Os profissionais envolvidos com avaliação psicológica ou educacional encontrarão bom material para reflexão. Recomenda-se para estudantes em nível de graduação ou pós-graduação, não somente por conter textos fáceis de ler, mas também por apresentar uma construção seguindo os padrões internacionais, servindo, portanto, como modelo na elaboração de textos científicos. 